\title{
Uma estratégia visual para a Feira da Panair
}

\author{
A visual strategy for the Panair Market
}

DA SILVA, Diego Souza; Graduando; Universidade Federal do Amazonas

diiegosilver@gmail.com

DA SILVA, Matheus Ricardo Muniz; Graduando; Universidade Federal do Amazonas

matheusricardo7424@gmail.com

FALCÃO, Franciane da Silva; Doutora; Universidade Federal do Amazonas

francianefalcao@ufam.edu.br

\section{Resumo}

Este artigo apresenta pesquisa e desenvolvimento de Identidade Visual para a Feira da Panair, o projeto foi orientado dentro da disciplina de Metodologia do projeto em Design, ministrado no curso de Design da UFAM - Universidade Federal do Amazonas. Entende-se que a identidade integra os aspectos culturais e mercadológicos da feira. Com base em referências do Design Visual, argumenta-se a importância do melhor planejamento gráfico da feira. As referências e o levantamento de dados nortearam as decisões do projeto e proporcionaram o encontro de uma solução visual voltada às necessidades do consumidor e do feirante.

Palavras Chave: comércio; feira regional; identidade visual.

\section{Abstract}

This article presents research and development of Visual Identity at the Panair Fair, the project was oriented within the discipline of design methodology, of the Design graduation at federal university of Amazonas. Methodology of design. It is understood that an identity integrates the cultural and marketing aspects of the fair. Based on the references of Visual Design, the importance of the best graphic planning of the fair is argued. The references and the data collection guided the project's decisions and provided a meeting of a visual solution focused on the needs of the consumer and the marketer.

Keywords: trade; regional market; visual idenity.

\section{Introdução}

Cada vez mais nos tornamos uma sociedade visual, expressando-nos através de cores, texturas, imagens e formas, utilizando o Design como instrumento de comunicação e inovação. Um dos fatores primordiais para essa forma de expressão se dá através da identidade visual, seja ela de uma empresa, de uma instituição ou de um território.

A identidade Visual corporativa assume o papel de promover uma promessa de valores ao seu público através de sua narrativa gráfica, traduzindo políticas e culturas em um elemento unificador, proporcionando identidade e unidade a uma instituição ou a uma empresa. 
Nesse contexto, as corporações preocupam-se cada vez mais em transparecer a sua comunicação com o usuário e sentem a necessidade de humanizar a sua aproximação com o seu cliente, utilizando o design como estratégia.

A importância de uma assinatura visual para a Feira da Panair se faz evidente devido à ausência de um símbolo que estabeleça as qualidades multifacetadas do seu sistema, isto contribui para a sua desvalorização cultural. A presença marcante desta Feira no contexto cultural da cidade de Manaus requer um melhor posicionamento e melhoria da sua imagem corporativa. Por conseguinte, propõe-se desenvolver conceitos e especificações para melhorar a aparência da Feira, tanto para o benefício do usuário, enquanto cliente, quanto para a mesma.

Compreendendo a importância do papel da identidade visual como o fator que promove as relações expressivas e culturais de uma empresa, esse artigo apresenta o desenvolvimento da assinatura visual da Feira da Panair, entendendo que a identidade visual busca integrar todos os aspectos visuais do lugar.

\section{A Feira da Panair}

As feiras consistem numa reunião de produtores e consumidores, em caráter periódico e temporário, para compra e venda de produtos característicos. No Brasil as feiras livres foram regulamentadas apenas no início do século XX. Boa parte da população utiliza a feira como local de compra de produtos da cesta básica, muitas delas voltadas para além do abastecimento alimentar, mas também para o artesanato.

Segundo AMOROSO (2015), a Feira da Panair constitui uma modalidade de mercado varejista ao ar livre, programada como serviço de utilidade pública e voltada para o abastecimento de gêneros alimentícios. Surgiu em meados de 1951, em Manaus, capital do estado do Amazonas. A Feira não possuía nenhum nome, era apenas um local convencional para comércio de alguns itens alimentícios como frutas, verduras e peixes. Só recebeu um nome anos depois, por conta de uma empresa de aviões aquáticos denominada Panair do Brasil que pousavam nas águas negras que circundam a região e na época era uma das mais famosas do país. A Panair do Brasil nasceu como subsidiária de uma empresa norte-americana em 1929. Sua extinção se deu por volta de 1965 e, após esse período, a Feira da Panair começou a se consolidar e atrair cada vez mais público. Em 1978 se estabeleceu como um dos maiores comércios da cidade, e desde então tem sido uma fonte de renda significativa para os comerciantes. A feira é muito conhecida pela enorme quantidade de produtos naturais. A maior busca atualmente é no mercado pesqueiro, e também no mercado de frutas, verduras e vegetais. Que vem principalmente sendo trazidos de outros lugares do Amazonas através do Rio Negro.

A atenção deste projeto está voltada especificamente para a natureza das formas e significados que circundam o exterior e o interior da feira, significados como seus produtos naturais típicos da região e o local onde se situa a feira, bem ao porto de Manaus. SILVA (1936), entende ser a feira um local privilegiado para tais manifestações que considera culturais, "núcleos que imprimem uma nota pitoresca em vários cantos da nossa terra".

A Panair, como uma das expressões das tradições urbanas da cidade de Manaus, compromete a sua valorização e representatividade com a falta de uma identidade, tal fato pautou a nossa pesquisa e linha de atuação para a construção de uma assinatura visual. Primeiramente 
procuramos entender os objetivos e aspectos da feira, o público a quem se destina e o território onde se localiza. Em seguida, buscamos, através do Design, desenvolver o projeto gráfico de identidade visual.

\section{Metodologia e pesquisa para a definição da identidade visual da Feira da Panair}

VÁSQUEZ (2011, p.9) reforça que "a identidade visual deve ser para que cumpra seus propósitos: única e intransferível, atemporal e constante, consistente e coerente, objetiva e adaptável". Para ele, a unicidade estava na reunião dos elementos específicos que passassem uma mensagem singular, autêntica e clara, assim exercendo uma eficácia na sua função enquanto identidade. Tendo compreendido isso, demos início ao processo de elaboração da marca.

Para o desenvolvimento, a dupla de criação, juntamente com a professora orientadora, realizaram um estudo aprofundado do briefing escolhido, colocando em evidência alguns fatores cruciais para que se iniciasse o processo de criação, tais como público-alvo, mercado de vendas e o contexto regional-cultural.

Iniciamos pelo mercado de venda, que aponta que o consumidor é atraído pela qualidade dos produtos da feira e a tradição de buscar um local para consumo de produtos alimentícios regionais. De acordo com o briefing e pesquisa sobre a história da feira, a marca deveria transparecer a presença marcante na cidade e os seus valores tanto mercadológicos como culturais.

Como público-alvo, foram identificados homens em sua maioria, acimas dos 30 anos e em sua maioria da classe $B$, consideradas como pessoas que apreciam os alimentos regionais, valorizando desde os itens mais marcantes como carnes e frutas típicas até os temperos. Também pode-se definir como público-alvo os feirantes que contribuem para que o sistema da feira continue ativo. A relação socioeconômica que esse espaço proporciona a esses produtores ao longo dos anos, gera um sentimento emocional de tradição da atividade feirante.

Os produtos ofertados são exclusivamente regionais e abastecem a cidade. Desse modo, a culinária manauara mantém-se enraizada por dispor de um espaço como esse, que vai além de uma atividade de subsistência, mas contribui também para a constância do consumo da culinária local.

Partimos então para a análise do briefing, em que definimos os objetivos e necessidades, bem como seus diferenciais. Os objetivos do projeto foram: desenvolver uma identidade de marca para a Feira, que tem com escopo ratificar a sua importância cultural e mercadológica. A marca deveria destacar o conjunto de elementos locais que traduzissem cultura e mercado.

A partir do briefing, ocorreu um a reunião de brainstorming para definir as palavras chaves que nortearam o projeto, foi elaborado então, um diagrama de palavras como o intuito de afunilar a proposta de valor. 
Figura 1. Diagrama de Palavras chaves

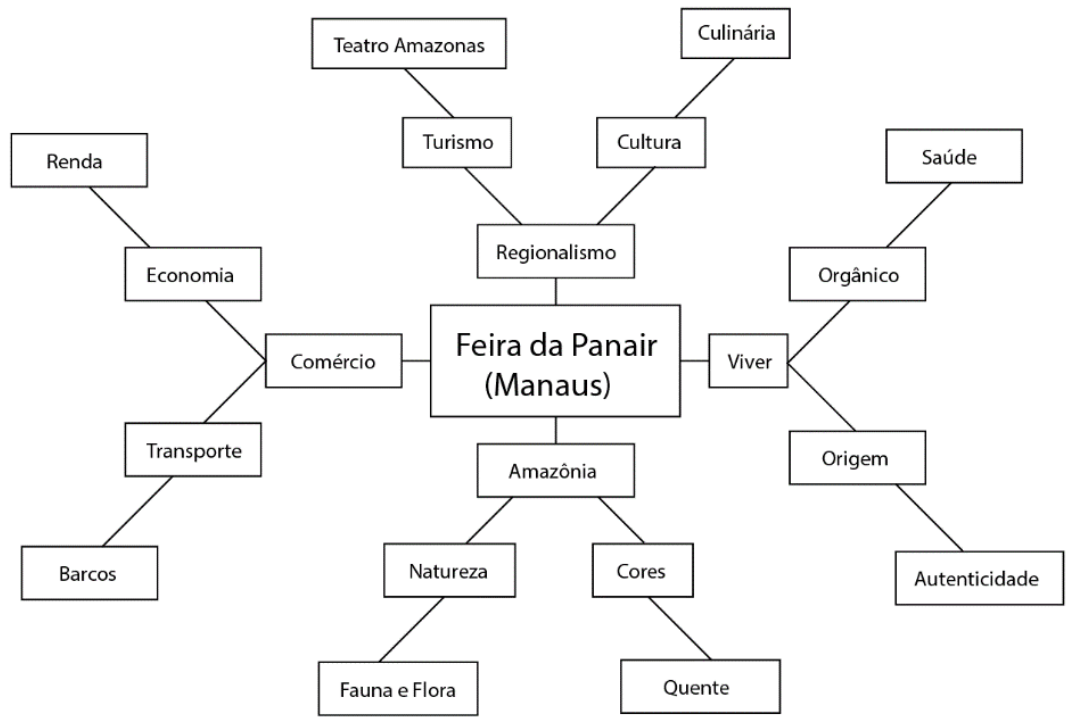

Fonte: elaborada pelos autores.

Em seguida, foi desenvolvido um moodboard com a finalidade de relacionar o diagrama de palavras anteriores, para assim dar-se início ao planejamento da marca.

Figura 2. Moodboard projetual

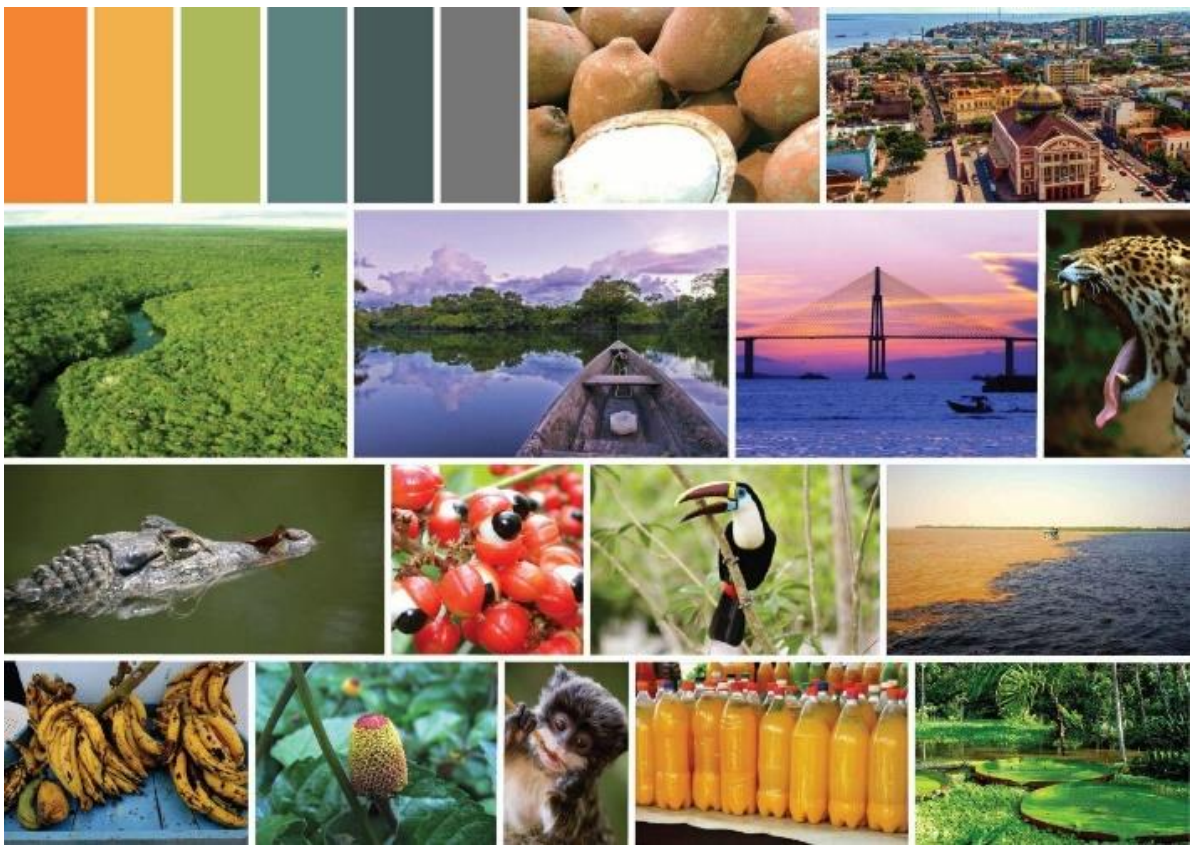

Fonte: elaborada pelos autores.

A partir disso, iniciou-se o processo de definição de metas projetuais. 


\section{Estratégias e metas projetuais}

O Comitê de Melhor Prática de Branding, (2010a, p.6) define que "marca eficaz é o conjunto de signos e representações, organizadas em rede significante, que identifica um produto/serviço/empresa ou entidade, diferenciando-o de seus concorrentes ou similares." Ou seja, eficaz é marca que determina a preferência de seus consumidores, bem como a admiração de seus interlocutores.

De acordo com os preceitos básicos de identidade visual, foi definido que a estratégia principal é: Aumentar o raio de notoriedade da feira através de uma marca chamativa, provocando um interesse maior nas pessoas através de cores, formas e da nova ideia de ter uma representação visual da Feira.

Com a premissa da estratégia consolidada, foram estabelecidas as seguintes metas:

$\checkmark$ Representar visualmente a regionalidade e a cultura local;

$\checkmark$ Aplicar os conceitos definidos de forma simples e objetiva;

$\checkmark$ Através do apelo visual (cor, forma, tipografia) provocar fortes reações emocionais;

$\checkmark$ Dar suporte gráfico para a feira;

$\checkmark$ Aumentar a popularidade da Feira da Panair através da Identidade Visual.

Em seguida, foram pesquisadas marcas similares que expressem com esmero, os conceitos, as formas, as cores e os significados ocultos de tudo o que querem representar, de uma forma clara, direta e coesa.

\section{Assinatura Visual}

Como estamos tratando de algo que já faz parte da cultura do cidadão amazonense, a identidade visual precisa se perpetuar junto com a feira. A necessidade de se manter, geração após geração, para que a marca nunca fique ultrapassada, e nunca se perca.

As pessoas que costumam frequentar a feira gostam de se sentir bem, de serem bem tratadas e de ter um serviço de qualidade. A praticidade que torna o fluxo do comércio mais natural e orgânico é a mesma que precisa circundar a imagem que é passada para a população. A praticidade também se encaixa na fácil identificação e principalmente na internacionalização da identidade visual. Sabemos que a maior parte de consumidores são da região, mas a feira chama a atenção de muitas pessoas de fora, do Brasil e do mundo. O símbolo precisa transmitir uma mensagem que seja clara em qualquer língua, e em qualquer lugar.

Estando há quase 70 anos entre os amazonenses, a Feira já se misturou com a cultura local e tem praticamente uma força própria, o que nos mostra que é fundamental trazer para a visualização das pessoas, elementos que remetam à cidade, à cultura e aos ideias do povo amazonense.

A sobrevivência da Feira ao tempo não se dá apenas por um fator mercadológico, mas também pela cumplicidade que existe no meio social em que está inserida. Os vendedores possuem uma parceria significativa uns com os outros, o que fortalece a maneira como o comércio funciona. Justamente pela identificação social e econômica que existe, acabam se aproximando muito mais. Pensando nesses 4 conceitos teóricos básicos, escolhemos 4 conceitos visuais para a construção da marca, que são: embarcações, encontro das águas, pôr do sol e o tucumã. 
A marca utiliza duas formas geométricas básicas para a construção de toda a sua estrutura, o círculo e o quadrado. O círculo não tem começo nem fim, ele perpetua uma ideia. Também pertence às formas fundamentais de valor, dessa forma, nunca irá desaparecer e sempre estará em constante renovação. São a representação do que de mais grandioso o ser humano conhece, o sol, a terra, a lua. Círculo é movimento, poder, energia. Já o quadrado vem para dar um contraponto visual, trazendo uma resistência, equilíbrio, uniformidade, eficiência, profissionalismo. Traz a tradição, a cultura, os costumes, o reflexo de um povo. A leitura dessas formas geométricas na marca teve uma hierarquia significativa.

Figura 3. A marca

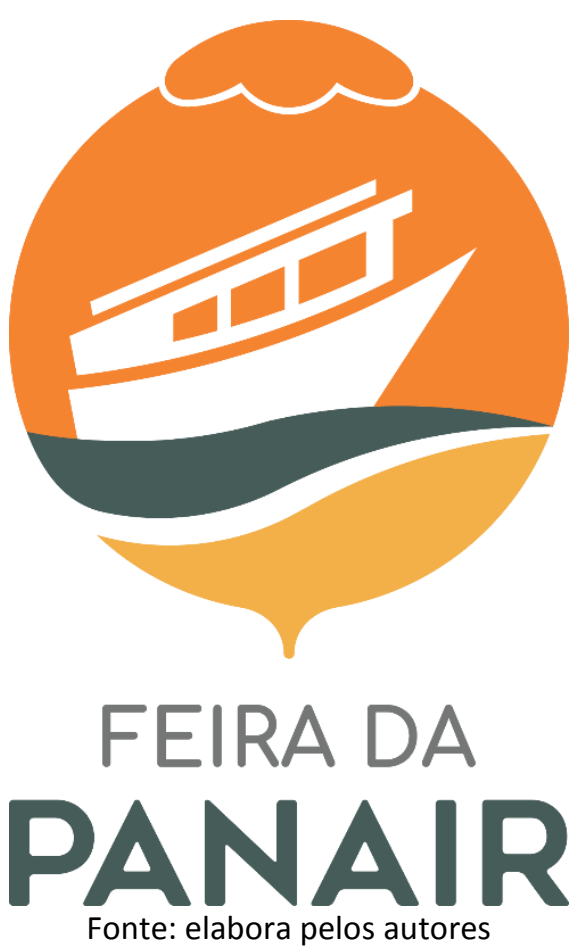

As embarcações são praticamente o fator principal que movimenta o comércio da feira, visto que a maioria dos produtos chegam via fluvial. Este foi o elemento principal trabalhado na composição do símbolo.

O encontro das águas é um dos maiores símbolos do estado do Amazonas, é um fenômeno natural que acontece por conta de fatores climáticos, geológicos termais e até mesmo pelo nível de acidez no rio. O mais famoso deles é o encontro do Rio Negro com o Rio Solimões, que é conhecido no mundo todo e foi utilizado por conta do seu aspecto visual de fácil reconhecimento.

Muitos dos produtos que trazidos pelas embarcações, costumam chegar no amanhecer, ou no fim da tarde, portanto, o pôr do sol é uma representação visual bem característica e foi utilizado de forma sutil na construção principal da marca.

Por se tratar de um comércio, utilizar na sua composição gráfica um dos seus produtos é essencial para o símbolo, portanto escolhemos o tucumã, que é um fruto da região amazônica que tem diversas utilidades, principalmente na culinária amazonense. 
Figura 4. Conceitos visuais - embarcações

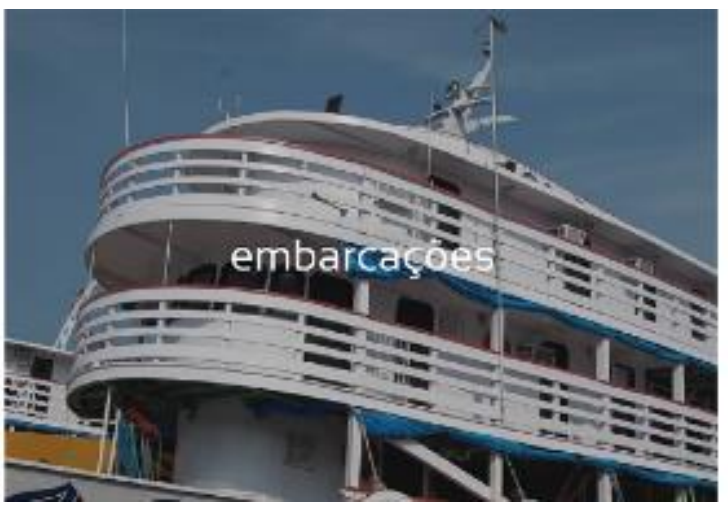

Fonte: elaborada pelos autores

Figura 5. Conceitos visuais - encontro das águas
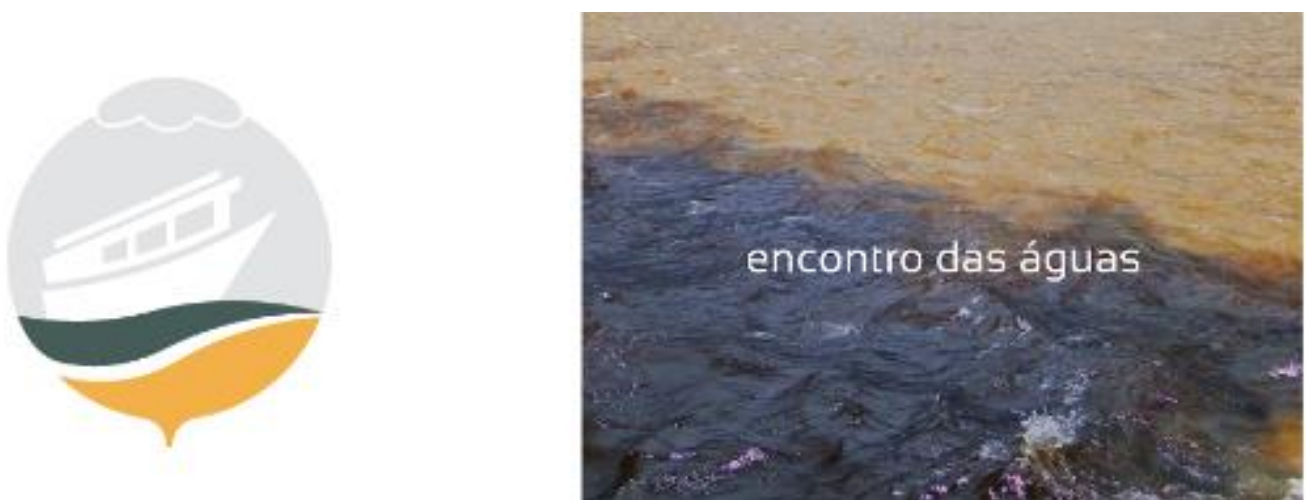

Fonte: elaborada pela autores

Figura 6. Conceitos visuais - pôr do sol
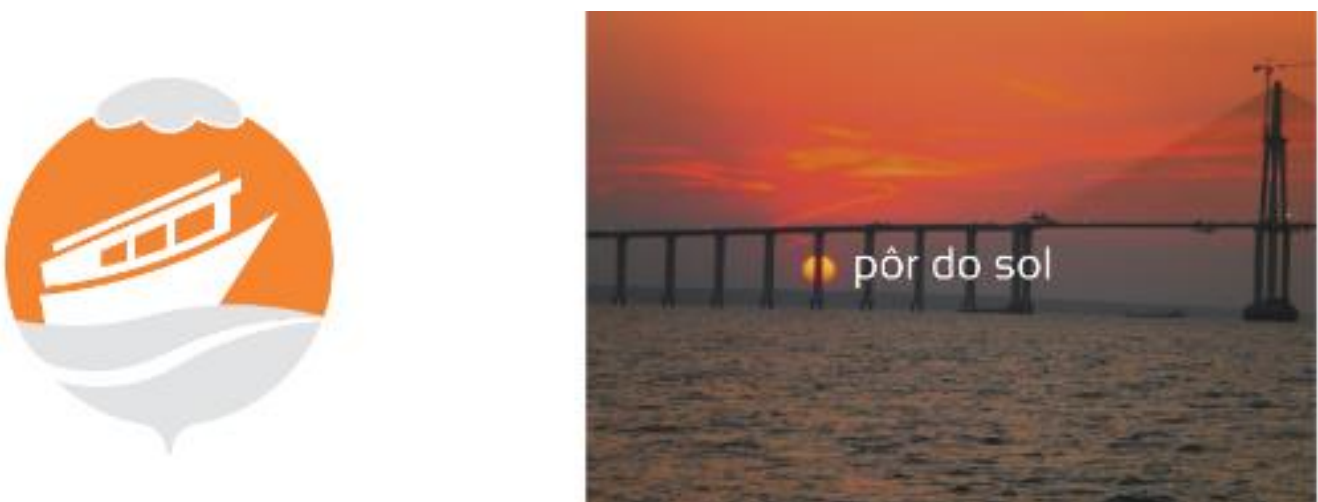

Fonte: elaborada pelos autores 


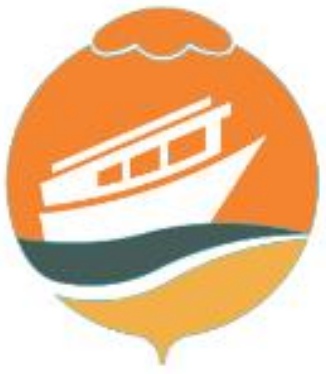

Figura 7: Conceitos visuais

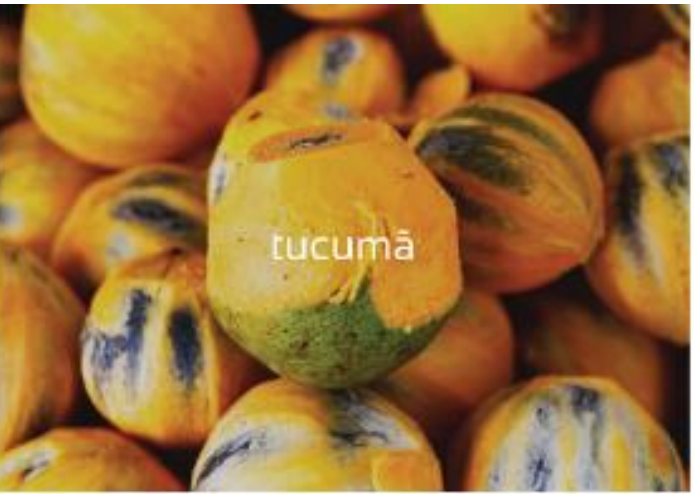

Fonte: elabora pelos autores

Para chegar a um resultado significativo de uma paleta de cores que traduza as informações visuais que a marca precisa transmitir, foi feito um estudo através de manchas visuais que nos mostraram as maiores incidências cromáticas na ambientação da cidade de Manaus e no estado do Amazonas. Associando também, aos significados de cada cor para despertar e representar os conceitos idealizados previamente para a marca. Como estamos trabalhando com a utilização de 4 elementos principais para serem base de qualquer área em que vamos trabalhar, com as cores não foi diferente.

Quatro foram determinadas: azul, cinza, amarelo e laranja. O branco entra como uma cor de harmonização. Nos conceitos sentimentais, nós temos o azul como representação de destreza, seriedade e disciplina, já o cinza, traz a sofisticação e a elegância que a feira pode oferecer daqui pra frente, e mesmo da forma mais simples. O amarelo simboliza alegria e otimismo, alegria no trabalho, alegria para movimentar o comércio, a cidade, pensando sempre em um futuro melhor e promissor. O laranja traz o sucesso, o encorajamento e a determinação. Por fim o branco, a mistura de todas as cores, de todas as pessoas, a pureza, a paz e a harmonia.

Visando ao lado das representações visuais, o azul e o amarelo, em conjunto, foram as cores escolhidas para simbolizar o encontro das águas, que é formado pelo Rio Negro e o Rio Solimões. 0 fruto tucumã, que compõe praticamente toda a forma, recebe a cor laranja pela tonalidade natural da casca, mas por dentro temos o amarelo do fruto e o azul do caroço. O pôr do sol também é representado pela cor laranja, mesma do fruto. A cor branca, no elemento que simboliza a embarcação, remete as madeiras utilizadas nos barcos, que, em sua maioria, são pintadas na cor branca. 


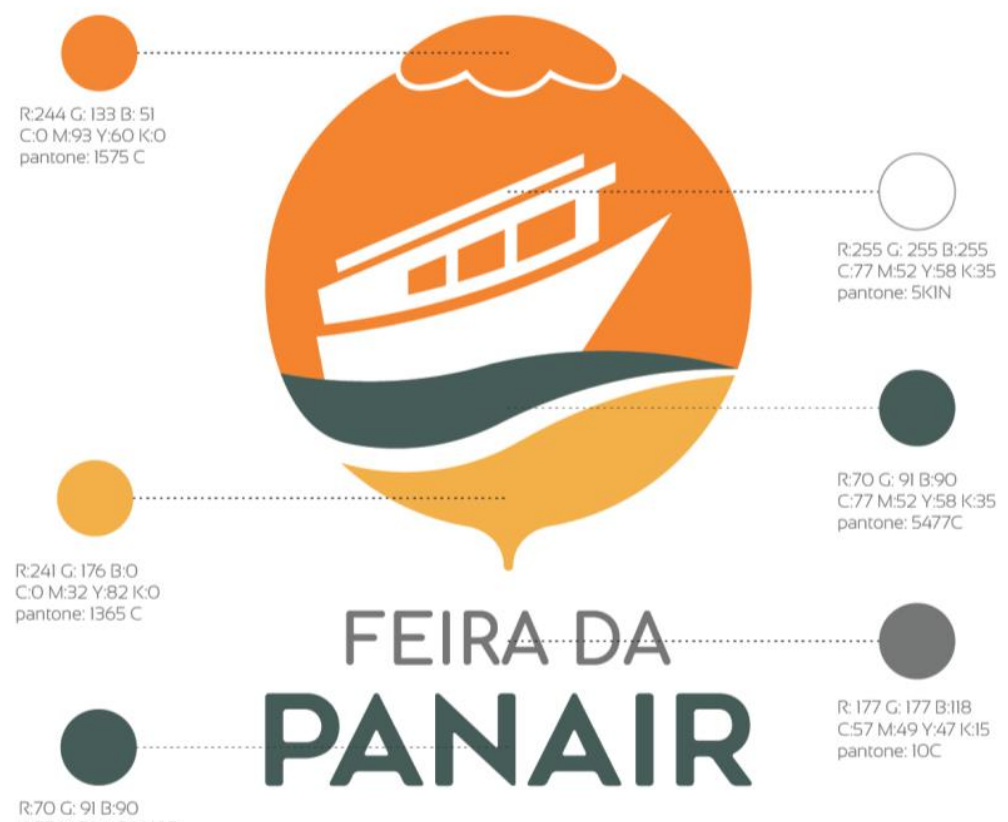

Fonte: elaborada pelos autores

A tipografia escolhida tem um valor morfológico importante na composição geral da marca, visto que suas formas arredondadas dão continuidade aos conceitos pré-estabelecidos.

Figura 9: Tipografia

\section{GEOMETOS ROUNDED}

A B CDEFGHIJKLMNOPORSTUVWXYZ 0123456789

! ? ( )/ \$\#., ; : - * * +\%)]" «")

\section{Comfortaa}

ABCDEFGHIJKLMNOPQRSTUVWXYZ abcdefghijklmnoparstuvwXyz 0123456789

? ? ( )/ \$\#., ;: - * + + \% \}]" "()

Fonte: elaborada pelos autores

A marca poderá ser utilizada tanto para meios digitais, como sites, redes sociais e afins, quanto para meios impressos, como cartazes, folders, vestimentas, embalagens e sinalização. Sua 
aplicação também será fundamental na arquitetura, para padrões visuais e identificação.

\section{Conclusão}

Com a aplicação de metodologias e embasamentos que o design proporciona voltados para as áreas de conceituação e desenvolvimento de identidades visuais, visando à mesclagem cultural, social e mercadológica, conseguimos transformar o jeito como os negócios são vistos. A importância da representatividade gráfica para um comércio hoje é indispensável. A experiência vivenciada por todas as pessoas envolvidas, desde os vendedores até os compradores, se torna única a partir do momento em que a representação dos valores e da cultura do local onde estão vivendo é traduzida em ambientes onde elas estão presentes.

Tendo em vista o valor cultural do projeto, podemos afirmar que ele também serve de base e influência para outros projetos e estudos posteriores, estimulando assim, situações paralelas a adotarem essas metodologias e fundamentos para a concepção de novas identidades visuais.

\section{Referências}

AMOROSO, Raimundo. Depoimento sobre a História da Feira da Panair. YOUTUBE, 16 de abril de 2015. Disponível em < https://www.youtube.com/watch?v=DbJazz9xgQY>. Acesso em 03 de março de 2018.

REZENDE, Marco Antonio Amaral. Guia de Identidade Visual e Naming. São Paulo, ABAassociação Brasileira de Anunciantes, 2010.

SILVA, Antonio Carlos Simoens. Feiras Livres no Distrito Federal: Hábitos Costumes Populares. Rio de Janeiro, Oficina Gráfica do Jornal do Brasil, 1936.

VÁSQUEZ, Ruth Peralta. Identidade de marca, gestão e comunicação. São Paulo, Revista Organizacion, 2011. 